\title{
PEDIATRIC REVIEW
}

\section{Musculoskeletal pain in overweight and obese children}

\author{
SM Smith ${ }^{1,2}$, B Sumar $^{1}$ and KA Dixon ${ }^{1}$
}

This review seeks to provide a current overview of musculoskeletal pain in overweight and obese children. Databases searched were Academic Search Complete, CINAHL, Medline, Proquest Health and Medical Complete, Scopus, Google Scholar, SPORTDiscuss and Trove for studies published between 1 January 2000 and 30 December 2012. We used a broad definition of children within a 3- to 18-year age range. The search strategy included the following terms: obesity, morbid obesity, overweight, pain, musculoskeletal pain, child, adolescent, chronic pain, back pain, lower back pain, knee pain, hip pain, foot pain and pelvic pain Two authors independently assessed each record, and any disagreement was resolved by the third author. Data were analysed using a narrative thematic approach owing to the heterogeneity of reported outcome measures. Ninety-seven records were initially identified using a variety of terms associated with children, obesity and musculoskeletal pain. Ten studies were included for thematic analysis when predetermined inclusion criteria were applied. Bone deformity and dysfunction, pain reporting and the impact of children being overweight or obese on physical activity, exercise and quality of life were the three themes identified from the literature. Chronic pain, obesity and a reduction in physical functioning and activity may contribute to a cycle of weight gain that affects a child's quality of life. Future studies are required to examine the sequela of overweight and obese children experiencing chronic musculoskeletal pain.

International Journal of Obesity (2014) 38, 11-15; doi:10.1038/ijo.2013.187

Keywords: adolescent; overweight; pain; musculoskeletal; disability; child health

\section{INTRODUCTION}

Worldwide childhood obesity has increased by $50 \%$ in the past 30 years, with $\sim 43$ million children under the age of five being reported as overweight. ${ }^{1}$ The WHO defines overweight and obesity as abnormal or excessive fat accumulation that may impair health. ${ }^{1}$ In Australia, obesity, as defined by WHO, continues to be a major public health problem with over $20 \%$ of school children being either overweight or obese ${ }^{2}$ and children from low socioeconomic areas being $70 \%$ more likely to be either overweight or obese. ${ }^{3}$ Central obesity, as measured by waist circumference, is thought to be a more reliable indicator of health problems than total body mass for people with a body mass index (BMI) of less than $35 .{ }^{4}$ Studies into obesity tend to report indices such as BMI and waist circumference. However, a definition of obesity and its clinical diagnosis is often difficult and remains controversial, with waist circumference, BMI and skin folds being the more common non-invasive measurements used. ${ }^{5} \mathrm{~A}$ number of reports suggest that overweight and obese children have subsequently developed short- and long-term health problems that continue into adult life. ${ }^{5,6}$ In particular, psychological comorbidities associated with being overweight or obese during childhood and adolescence are well documented. ${ }^{7,8}$ These health problems include social isolation, depression, loneliness and low self-esteem, and more recently depressive symptoms have been linked with cardiorespiratory fitness in obese adolescents. ${ }^{9,10}$ Obesity in children is a significant public health problem, and it has the potential to have an impact on a child's osteoarticular health, resulting in ongoing chronic pain.

In adults, obesity is associated with physiological disability, in particular joint and chronic conditions such as cardiovascular disease, diabetes and some cancers. ${ }^{1}$ Degenerative osteoarthritis and cartilage breakdown along with musculoskeletal pain have been reported as part of the disability spectrum related to obesity. ${ }^{11}$ These conditions significantly reduce a person's ability to exercise, and in addition chronic pain has been reported to negatively influence a person's quality of life. ${ }^{12}$ Given that being overweight or obese in adult life affects health and well-being, the potential for deleterious effects on the musculoskeletal system from being overweight or obese in childhood requires further attention.

Chronic nonspecific musculoskeletal pain in children and adolescents has been reported as a common occurrence. ${ }^{13-15}$ Children affected by chronic musculoskeletal pain have been found to have increased levels of anxiety and depression, as well as lower levels of activity. ${ }^{16}$ Recent reviews on general musculoskeletal pain identified the most frequent site of nonspecific musculoskeletal pain in children in the lower limbs, with some estimates suggesting that this affects $24 \%$ of children aged between 6 and 10 years of age. ${ }^{17,18}$ Interestingly, Tanamas and co-workers ${ }^{19}$ found that an increase in adiposity and fat distribution across the body is related to foot pain, and yet this relationship is not evident with an increase in muscle mass. Although psychological wellness in children can be linked with increased levels of activity, an understanding of the role of musculoskeletal pain on the activity levels of overweight and obese children appears to be limited. The aim of this review was to provide a current overview of musculoskeletal pain in overweight and obese children with a focus on osteoarticular changes and joint health, reporting of musculoskeletal pain and the impact of pain on activity, exercise and quality-of-life indices.

\footnotetext{
${ }^{1}$ Family and Community Health Research Group, School of Nursing and Midwifery, University of Western Sydney, Campbelltown, NSW, Australia and ${ }^{2}$ Centre for Pharmacology and Therapeutics, Imperial College, Chelsea and Westminster Campus, London, UK. Correspondence: Professor SM Smith, Family and Community Health Research Group, School of Nursing and Midwifery, University of Western Sydney, Locked Bag 1797, Penrith, NSW 2751, Australia.

E-mail: sheree.smith@uws.edu.au
}

Received 7 August 2012; revised 11 September 2013; accepted 21 September 2013; accepted article preview online 30 September 2013 ; advance online publication, 29 October 2013 


\section{MATERIALS AND METHODS}

This literature review was carried out using a systematic method ${ }^{20}$ described in the Preferred Reporting Items for Systematic Reviews and Meta-Analyses guideline. We developed a detailed protocol with prescribed inclusion and exclusion criteria to support the quality and consistency within the literature review process. Studies associated with children who were defined as overweight or obese had to meet the following criteria to be included: written in English, published after January 2000; age range of 2-18 years; and report musculoskeletal pain. The types of studies included in this review were randomised control trials, cohort studies, quasi-experimental studies, controlled before and after studies and patient reports. We excluded discussion papers, reviews, opinions and policy reports. A predefined search strategy was used to examine databases for publications; after excluding records that did not meet the eligibility criteria, ten studies were included for synthesis, and themes associated with musculoskeletal pain and overweight or obese children were generated.

\section{Search strategy and selection criteria}

Academic Search Complete, Cinahl, Google Scholar, Medline, Proquest Health and Medical Complete, Scopus, SPORTDiscuss and Trove databases were searched for studies published between 1 January 2000 and 30 December 2012. The literature review search strategy (Table 1) used a combination of MESH terms in the title/abstract for obesity and pain, limiting to children and teenagers, and used the following terms: obesity, morbid obesity, overweight, pain, musculoskeletal pain, child, adolescent, chronic pain, back pain, lower back pain, knee pain, hip pain, foot pain and pelvic pain.

Participants and definitions

For this literature review, a broad definition of childhood to include children and adolescents within a range from 3 years to 18 years of age was used. For musculoskeletal pain, terms such as joint pain and muscle pain either objectively or subjectively reported were accepted. For example, joint pain may include shoulder pain, foot pain and knee pain.

\section{Search outcome}

By searching the electronic databases, 70 records were retrieved. The reference list of each of the identified reports, reviews and original research articles were manually searched for additional studies, with a further 27 studies identified. Only manuscripts in English were considered for assessment. Three records were removed as duplicates. Abstracts for each of the 94 records had the inclusion criteria applied separately by two of the authors. The review flowchart outlines the records identified or excluded at each phase of the review process (Figure 1). Two authors
(BS and KD) independently assessed each abstract, and any disagreement was resolved by the third author (SMS). Heterogeneity of reported outcome measures was identified, and subsequently a qualitative analytic process of thematic analysis was undertaken. Braun and Clarke ${ }^{21}$ ( $p$ 79) suggest that thematic analysis is a process for 'identifying, analysing and reporting patterns (themes) within data'.

\section{Data abstraction}

On completion of the independent review of abstracts, full texts of the remaining ten manuscripts were sourced (Table 2). Each manuscript was critically appraised by each individual author and the data were summarised to develop the themes. Consensus on the themes was achieved by the three authors. This review, however, did not assess interventions for weight loss and/or general pain reduction; rather, it focused specifically on the ultimate goal of providing a current understanding of musculoskeletal pain associated with overweight and obese children. Three central themes associated with musculoskeletal pain in overweight and obese children were generated, and they comprised musculo-skeletal health, joint alignment and dysfunction, pain reporting and the impact of pain on physical activity, exercise and quality of life.

\section{RESULTS}

Impact of being overweight or obese on musculoskeletal health, joint alignment and dysfunction

Numerous studies report the significant impact of being overweight or obese on bone and joint health in adults. ${ }^{22-24}$ Key issues are primarily bone demineralisation, deformity, dysfunction and the associated pain due to these changes in body structures. In this review, we were able to identify three studies that reported dysfunction and/or deformity of bone structure in overweight or obese children who report pain. The first study examined orthopaedic complications in overweight children and adolescents and found a significantly higher prevalence of skeletal fractures compared with non-overweight subjects. ${ }^{25}$ Similarly, a Dutch study identified that overweight and obese children self-reported ankle and foot problems ${ }^{26}$ and potentially impacted on their ongoing joint health. More concerning was de Sá Pinto's study that reports the osteoarticular alterations in obese children who had a BMl above the 95th percentile with significantly higher reports of pain when compared with normalweight children. ${ }^{27}$ The study also found a higher frequency of genu valgum, commonly called 'knock-knee', (55.1\%) and a higher frequency of genu recurvatum, which is an excessive extension of

Table 1. Strategies used to search the literature on musculoskeletal pain in overweight and obese children

\begin{tabular}{|c|c|c|}
\hline Specific search elements & Steps in search process & Term combination \\
\hline \multirow[t]{5}{*}{ 'Characteristic' } & 1 & *Obesity/ \\
\hline & 2 & 'obes*'.ab,ti. \\
\hline & 3 & *Obesity, Morbid/ \\
\hline & 4 & *Overweight/ \\
\hline & 5 & 'overweight'.ab,ti. \\
\hline Combining characteristic terms & 6 & 1 or 2 or 3 or 4 or 5 \\
\hline 'Population' & 7 & limit 6 to ('child ( 6 to 12 years)' or 'adolescent ( 13 to 18 years)') \\
\hline \multirow[t]{3}{*}{ 'Symptom' } & 8 & *Pain/ \\
\hline & 9 & 'pain'ab,ti. \\
\hline & 10 & *Chronic Pain/ \\
\hline \multirow[t]{8}{*}{ 'Body region' } & 11 & *Back Pain/ \\
\hline & 12 & *Low Back Pain/ \\
\hline & 13 & ('knee' adj3 'pain').ab,ti. \\
\hline & 14 & ('hip' adj3 'pain').ab,ti. \\
\hline & 15 & ('foot' adj3 'pain').ab,ti. \\
\hline & 16 & ('musculoskeletal' adj3 'pain').ab,ti. \\
\hline & 17 & *Pelvic pain/ \\
\hline & 18 & ('pelvi*' adj3 'pain').ab,ti. \\
\hline Final search & 19 & 8 or 9 or 10 or 11 or 12 or 13 or 14 or 15 or 16 or 17 or 18 \\
\hline
\end{tabular}

$\beta$, final search was limited to English text human subjects, age range and undertaken between 1 January 2000 and 30 December $2012 . \alpha,{ }^{*}$ before the MESH term means focused and not exploded. $\mu$, ab.ti limits search to abstract and title. $\varphi$, indicates searching for term within three words of each other regardless of order. 


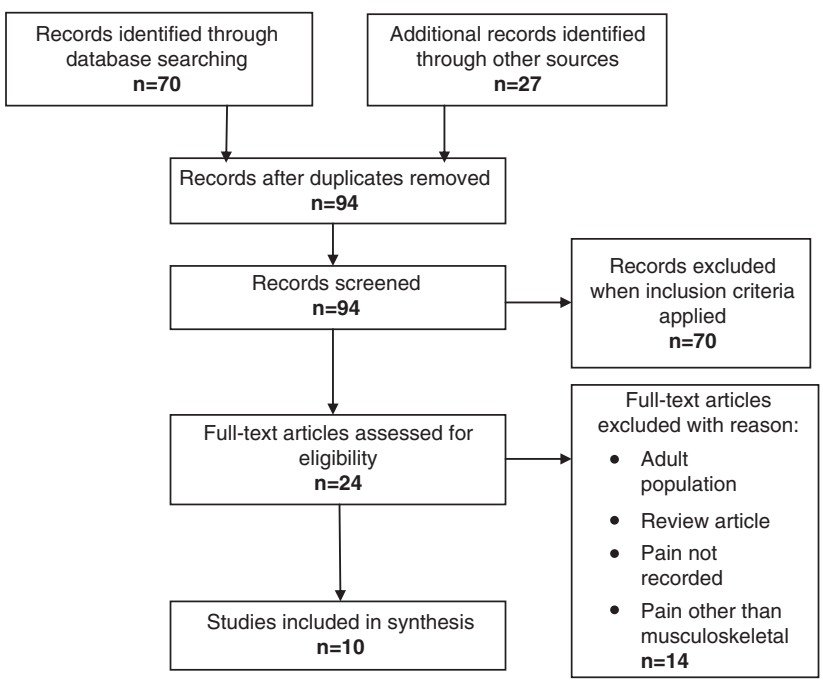

Figure 1. Retrieval of published studies process flow diagram.

the knee-joint, in obese children (24.2\%) compared with the control group of normal-weight children (2\%). These studies highlight a serious risk to the skeletal system of a child who is either overweight or obese and the pain associated with musculoskeletal dysfunction and deformity.

Musculoskeletal pain reporting in overweight and obese children Pain reporting is central to this review, and we sought to understand from the literature the most common sites of musculoskeletal pain, how pain is reported and any differences that occur within the studied populations of overweight and obese children. Of the studies reviewed, musculoskeletal pain was identified through medical chart review and/or self-report by parents and/or children. Two retrospective medical chart reviews of children and adolescents used musculoskeletal pain as the primary inclusion criterion in two differing patient populations: a paediatric clinical trial unit and paediatric pain clinic. ${ }^{25,28}$ Six prospective studies recorded pain from participating overweight and obese children and adolescents compared with normalweight children in a variety of settings. Two of these studies included participants from obesity clinics. ${ }^{27,29}$ One study was in a specialised orthopaedic service ${ }^{30}$ and in primary care, ${ }^{26}$ and the remaining two studies assessed children ${ }^{31,32}$ in a primary school setting.

The sites of pain in these overweight and obese paediatric populations differ in each study. Four studies reported musculoskeletal pain sites, for example, lower back, knees, ankles and feet, ${ }^{25-27,31}$ and one study reported neck pain. ${ }^{26}$ However, three studies reported nonspecific musculoskeletal pain without specifying the pain site. ${ }^{28,30,32}$ Interestingly, children who reported musculoskeletal pain in the back, hip, knee and/or ankle were found to have a significantly higher BMI than those without pain, with the odds of having joint pain increased by $10 \%$ for every $10-\mathrm{kg}$ increase of weight and an increase of 3\% for every unit increase in BMI. ${ }^{29}$ Recently, a study that sought to estimate overall and age-specific associations between obesity and musculoskeletal pain in children found a significant increase in pain in the lower extremities of extremely obese children across three age ranges encompassing children aged between 2 and 19 years compared with normal-weight children. ${ }^{33}$

During this review, we identified only one scale (other than a quality-of-life tool) that was specifically used to examine the impact of pain in obese children. Podeszwa ${ }^{30}$ used the Pediatric Outcomes Data Collection Instrument to determine obese children's overall health, pain and their ability to participate in activities of daily life and vigorous exercise. They found that older obese girls (age $>11$ and $<18$ ) had significant reduction in function, mobility and happiness, with a substantial increase in pain; however, obese boys had a greater reduction in mobility without an increase in pain compared with normal-weight boys. This evidence highlights the potential for significant disability in adult life, apart from chronic illnesses such as diabetes type 2 and heart disease, should these children continue to remain overweight or obese.

Impact of pain on activity, exercise and quality of life

Health-related quality-of-life tools have been extensively used in adult obesity studies; however, very little research on overweight and obese children has been reported in terms of quality-of-life indices. Recently, a small number of studies have sought to describe the impact of musculoskeletal dysfunction using the health-related quality-of-life tools. Taylor et al. ${ }^{25}$ identified overweight children through chart audit, dual X-ray absorptiometry scans and data from the impact of weight on quality-of-life adolescent questionnaire as having more musculoskeletal discomfort, impaired mobility and lowerextremity malalignment. These three health issues may have an impact on a child's quality of life and have been linked with a reduction in the likelihood of physical activity when compared with non-overweight children. Hainsworth et al. ${ }^{28}$ studied the health impacts on children who experience chronic pain using the health-related quality-of-life tool and identified that $48 \%$ of obese children experience musculoskeletal pain more than other types of pain such as headache or abdominal pain. The premise that a combination of chronic pain and obesity reduces physical functioning was a significant finding of Hainsworth's study, as was the finding that obesity and impaired physical functioning was six times higher than obesity alone in this chronic pain paediatric population. This research suggests that there may be a cyclic inter-relatedness between chronic pain, obesity and levels of physical activity.

Wilson et al. $^{34}$ confirm the association between physical activity and obesity as reported in Hainsworth's study. Wilson et al. found, in a population of obese children who were receiving treatment for musculoskeletal pain, that the parents often reported limitations in the child being able to participate in exercise and sports. Specifically, when parents are asked to report on their children's activity, the parents relate the child's activity levels to the child's weight, whereas children associate their activity level with their level of pain. Wilson et al. found that the relationship between being overweight or obese and pain may be partially mediated by physical activity levels. Both studies suggest a spiralling effect in which overweight and obese children with musculoskeletal pain reduce their activity, potentially contributing to further weight gain. With few studies in this area, clearly more research is required to develop a greater understanding of the impact of activity and exercise on overweight and obese children who cope with ongoing musculoskeletal pain and the effect on their short- and long-term quality of life.

\section{DISCUSSION}

There is substantive evidence from many countries that an increasing number of children are becoming overweight and obese. ${ }^{35}$ Most of the studies identified through this review were within specialist chronic pain or obesity paediatric clinic populations, and a small number of studies based in primary care or used electronic health records addressed the issue of obesity and musculoskeletal pain in children and adolescents.

The impact of being overweight or obese on a child's skeletal system has been reported in terms of joint health and dysfunction 
Table 2. Studies included in the review

\begin{tabular}{|c|c|c|c|c|c|c|c|}
\hline First author & Age (years) & Country & Year & Sample size & Type of study and measurement & Results & Determinant of overweight and obesity \\
\hline Podeszwa, DA & $2-18$ & USA & 2006 & 50 & $\begin{array}{l}\text { Prospective PODCl validation study using } \\
\text { BMI, PODCI and life satisfaction question }\end{array}$ & $\begin{array}{l}\text { Recorded impairment in sports } \\
\text { and pain in obese children } \\
\text { compared with normative data. } \\
\text { Data for this difference not } \\
\text { provided }\end{array}$ & $\begin{array}{l}\text { BMI for age exceeding 95th percentile } \\
\text { (based on growth charts developed by } \\
\text { the CDC that correct for gender } \\
\text { differences) }\end{array}$ \\
\hline Stovitz, S & $3-18$ & USA & 2008 & 135 & $\begin{array}{l}\text { Prospective descriptive cross-sectional } \\
\text { study using BMI and pain assessment. OR } \\
\text { of pain for the knee and hip in obese } \\
\text { children }\end{array}$ & $\begin{array}{l}\text { Knee: } \mathrm{OR}=1.13 \text { per } 10 \mathrm{~kg} \text { increase } \\
\text { in weight, } 95 \% \mathrm{Cl}: 1.01-1.29 . \\
\mathrm{OR}=1.04 \text { per unit increase in } \mathrm{BMI} \text {, } \\
95 \% \mathrm{Cl}: 1.01-1.08 \\
\mathrm{Hip:} \mathrm{OR}=1.29 \text { per } 10 \mathrm{~kg} \text { increase in } \\
\text { weight, } 95 \% \mathrm{Cl}: 1.05-1.60 \text {. } \\
\mathrm{OR}=1.09 \text { per unit increase in } \mathrm{BMI}, \\
95 \% \mathrm{Cl}: 1.03-1.16\end{array}$ & $\begin{array}{l}\text { BMI for age exceeding 95th percentile } \\
\text { (based on growth charts developed by } \\
\text { the CDC that correct for gender } \\
\text { differences) }\end{array}$ \\
\hline de Sa Pinto, AL & $7-14$ & Brazil & 2006 & 49 & $\begin{array}{l}\text { Prospective cross-sectional study using } \\
\text { BMl, limb flexibility, posture examination, } \\
\text { clinic questionnaire, tender points and } \\
\text { fibromyalgia criteria. Frequency of genu } \\
\text { valgum and genu recurvatum in obese } \\
\text { children compared with normal-weight } \\
\text { children }\end{array}$ & $\begin{array}{l}\text { Genu valgum: } 55.1 \% \text { vs } 2 \% ; \\
P<0.0001 \\
\text { Genu recurvatum: } 24.2 \% \text { vs } 2 \% \text {; } \\
P<0.001\end{array}$ & $\begin{array}{l}\text { BMI for age exceeding 95th percentile (as } \\
\text { determined by the National Health and } \\
\text { Nutrition Examination Survey) }\end{array}$ \\
\hline Bell, LM & $7-15$ & Australia & 2011 & 283 & $\begin{array}{l}\text { Cohort study using BMI, structured } \\
\text { interview, medical assessment, } \\
\text { anthropometrics and fasting blood } \\
\text { investigations, including oral glucose } \\
\text { tolerance test }\end{array}$ & $\begin{array}{l}\text { Chi-square } P=0.010 \\
\text { OR compared with controls } \\
\text { For overweight children: } 1.53 \\
\text { For obese: } 4.09\end{array}$ & $\begin{array}{l}\text { Based on international age- and gender- } \\
\text { specific BMI cutoffs }\end{array}$ \\
\hline Taylor, ED & $8-16$ & USA & 2006 & 355 & $\begin{array}{l}\text { Retrospective medical chart review records } \\
\text { using BMI, IWQOL-A and DXA scans }\end{array}$ & $\begin{array}{l}\text { OR: } 4.45 ; 95 \% \text { Cl: } 1.6-13.2 \\
P=0.0053\end{array}$ & $\begin{array}{l}\text { BMI for age exceeding 95th percentile (as } \\
\text { determined by the National Health and } \\
\text { Nutrition Examination Survey) }\end{array}$ \\
\hline Bell, LM & $6-13$ & Australia & 2007 & 177 & $\begin{array}{l}\text { Cohort study using BMI, structured } \\
\text { interview, medical assessment, } \\
\text { anthropometric and fasting blood } \\
\text { investigations, including oral glucose } \\
\text { tolerance test }\end{array}$ & $\begin{array}{l}\text { For musculoskeletal pain: } \\
\text { OR (with every increase of } 1.0 \text { in } \\
\text { BMI } z \text {-score): } 2.54 \\
95 \% \mathrm{Cl} \text { of OR: } 1.41-4.59 \\
\text { Wald } P \text {-value (for BMI } z \text {-score): } \\
0.003\end{array}$ & $\begin{array}{l}\text { Children were classified as overweight or } \\
\text { obese using the Cole et al. }{ }^{16} \text { age- and } \\
\text { gender-specific overweight and obese } \\
\text { cutoffs of BMI for children }\end{array}$ \\
\hline Hainsworth, KR & $8-18$ & USA & 2009 & 319 & $\begin{array}{l}\text { Retrospective review of medical records } \\
\text { using BMl, anthropometrics, clinical and } \\
\text { diagnostic data, self report of pain and } \\
\text { HRQOL scores }\end{array}$ & $\begin{array}{l}\text { Differences in musculoskeletal/ } \\
\text { orthopaedic pain characteristics } \\
\text { between the three weight groups } \\
\text { was substantial but not significant } \\
\text { with } P=0.054\end{array}$ & $\begin{array}{l}\text { BMI was measured using the US Centre } \\
\text { for Disease Control and Prevention } 2000 \\
\text { growth charts for sex and age }\end{array}$ \\
\hline Krul, M & $2-17$ & Netherlands & 2009 & 2,459 & $\begin{array}{l}\text { Retrospective review of Dutch National } \\
\text { Survey of Family Practice using Survey } \\
\text { database and face-to-face interview }\end{array}$ & $\begin{array}{l}\text { OR: } 1.92 ; 95 \% \text { Cl: } 1.15-3.20 \\
P \leqslant 0.05\end{array}$ & $\begin{array}{l}\text { A standard developed for age-specific } \\
\text { overweight and obesity BMI cutoff points } \\
\text { in Dutch children was used to determine } \\
\text { the presence of overweight and obesity } \\
\text { in the study population }\end{array}$ \\
\hline Wilson, AC & $8-18$ & USA & 2011 & 118 & $\begin{array}{l}\text { Retrospective review of medical chart } \\
\text { using Clinic questionnaire, BMI and CALI- } 21 \\
\text { for activity limitation }\end{array}$ & $\begin{array}{l}\text { A significantly higher rate of } \\
\text { overweight and obesity was } \\
\text { observed among youth with } \\
\text { chronic pain compared with a } \\
\text { normative sample. }\end{array}$ & $\begin{array}{l}\text { CDC's online paediatric BMI calculator, } \\
\text { which was used to obtain BMI, BMI } \\
\text { percentile and BMI }\end{array}$ \\
\hline Adams & 2-11 (and 12-19) & USA & 2012 & 913178 & $\begin{array}{l}\text { Cross-sectional study examined } \\
\text { associations between weight class and } \\
\text { diagnosis of fractures, sprains, dislocations } \\
\text { and pain }\end{array}$ & $\begin{array}{l}\text { Significant increase in pain of the } \\
\text { lower extremities in extremely } \\
\text { obese children between } 2 \text { and } 5 \\
\text { years of age }(\mathrm{OR}=1.60,95 \% \mathrm{Cl} \\
1.16-2.20) \text { compared with their } \\
\text { normal weight counterparts and } \\
\text { for children } 6-11 \text { years extremely } \\
\text { obese }(\mathrm{OR}=1.31,95 \% \mathrm{Cl} \\
1.16-1.48), \text { moderately obese } \\
(\mathrm{OR}=1.24,95 \% \mathrm{Cl} 1.13-1.35) \text { and } \\
\text { overweight }(\mathrm{OR}=1.17,95 \% \mathrm{Cl} \\
1.07-1.28) \text { compared with their } \\
\text { normal weight counterparts }\end{array}$ & $\begin{array}{l}\text { Definitions for overweight and obesity } \\
\text { based on sex-specific BMI-for-age growth } \\
\text { charts developed by CDC and WHO }\end{array}$ \\
\hline
\end{tabular}

Abbreviations: BMI, body mass index; CDC, Center for Disease Control; DXA, dual X-ray absorptiometry; HRQOL, health-related quality of life; IWQOL-A, impact of weight on quality-of-life adolescent questionnaire; PODCl, Paediatric Outcomes Data Collection Instrument.

resulting in more ankle, foot and knee problems than children who are within a normal-weight range for their age. ${ }^{26}$ Obesity is associated with pain, joint dysfunction ${ }^{27}$ and bone fractures. ${ }^{25}$ The progression of these osteoarticular changes into adult life, if weight management is not achieved, could lead to the need for ongoing orthopaedic treatment. ${ }^{33}$ Overweight and obese children reported musculoskeletal pain primarily due to changes within articulating joints such as knee and ankle, and as a result of fractures. ${ }^{25-27}$ Kessler's and other studies regarding bone fractures report significantly higher rates of factures in overweight and obese children, yet pain in these studies is not reported. ${ }^{36-39}$

From this review, it was found that children and their parents may report pain and activity differently. In the context of activity, children linked their pain with levels of activity, whereas parents associated activity with the child's weight. ${ }^{34}$ Therefore, the way pain is self-reported may require further validation from the perspectives of both parent and child. The relationship between increase in BMI, weight and pain demonstrates a risk factor for damage to the musculoskeletal structure, and this damage is often expressed by the child as pain. ${ }^{25,26}$ Evidence is emerging to suggest that a reduction in physical functioning of obese and overweight children may occur and be evident through the child's expression of pain, further impacting on their self-esteem resulting in a poorer quality of life. ${ }^{25,28,30}$ Changes to the musculoskeletal system in overweight and obese children have been shown to negatively influence motor performance, including muscle strength, balance and walking, through changes in plantar flexion during the swing phase of walking, resulting in a flatter foot. $^{40-44}$ Hip and knee flexion is also affected in obese children owing to an increase in concentric contraction of hip flexors, ${ }^{45}$ creating higher energy transfer and loads across hip joints, ${ }^{46}$ resulting in a change in gait to cope with the child's increased body mass. Therefore, the reporting of musculoskeletal pain by overweight children may reflect a significant marker of a reduction in osteoarticular health and changes to skeletal structure. In reviewing the literature associated with obese and overweight children, there appears to be links between bone health, pain, physical activity and quality of life, and these links may be important if the issue of musculoskeletal pain in this group of children is to be addressed. 


\section{CONCLUSION}

This review sought to identify the extent of musculoskeletal pain in overweight and obese children as reported in literature. The emerging evidence suggests that being overweight or obese has a significant impact on the health and well-being of these young people and may contribute to ongoing health problems such as musculoskeletal pain and bone/joint dysfunction in later life. The cumulative effect of children being overweight or obese and experiencing musculoskeletal pain requires further investigation.

\section{CONFLICT OF INTEREST}

The authors declare no conflict of interest.

\section{ACKNOWLEDGEMENTS}

We thank Geoff Lattimore, University of Western Sydney's medical research Librarian, for his assistance with the database searches and strategy.

\section{REFERENCES}

1 World Health Organization. Obesity and Overweight Fact Sheet No. 311 2011; http://www.who.int/mediacentre/factsheets/fs311/en/.

2 Australian Bureau of Statistics. National Health Survey: Summary of Results, 2007-2008. Report No. 4364.0, Canberra, 2009b.

3 Australian Institute of Health and Welfare. Headline indicators for children's health, development and wellbeing, 1-151, Canberra, 2011.

4 Department of Health and Ageing. Measure Up. 2010; http://www.health.gov.au/ internet/abhi/publishing.nsf/Content/Weight, + waist + circumference + and + BMI-Ip\#overweight.

5 Kiess W, Galler A, Reich A, Muller G, Kapellen T, Deutscher J et al. Clinical aspects of obesity in childhood and adolescence. Obes Rev 2001; 2: 29-36.

6 Cruz ML, Shaibi GQ, Weigensberg MJ, Spruijt-Metz D, Ball GD, Goran MI. Pediatric obesity and insulin resistance: chronic disease risk and implications for treatment and prevention beyond body weight modification. Rev Nutr 2005; 25: 435-468.

7 Puder JJ, Munsch S. Psychological correlates of child obesity. Int J Obes 2010; 34: s37-s43.

8 Hebebrand J, Herpertz-Dahlmann B. Psychological and psychiatric aspects of pediatric obesity. Child Adolesc Psychiatry Clin N Am 2008; 18: 49-65.

9 Puhl RM, Latner JD. Stigma, obesity and the health of the nation's children. Psychol Bull 2007; 133: 557-580.

10 Shomaker LB, Tanofsky-Kraff M, Zocca JM, Field SE, Drinkard B, Yanovski JA. Depressive symptoms and cardiorespiratory fitness in obese adolescents. $J$ Adolesc Health 2012; 50: 87-92.

11 Mazzuca SA, Brandt KD, Lane KA, Chakr R. Malalignment and subchondrial bone turnover in contralateral knees of overweight/obese women with unilateral osteoarthritis: implications for bilateral disease. Arthritis Care Res 2011; 63: 1528-1534.

12 Marcus D. Obesity and the impact of chronic pain. Clin J Pain 2004; 20: 186-191.

13 Hakala P, Rimpela A, Salminen JJ, Virtanen SM, Rimpela M. Back, neck and shoulder pain in Finnish adolescents: national cross sectional surveys. Br Med J 2002; 325: 743-746.

14 El-Metwally A, Salminen JJ, Auvinen A, Kautiainen H, Mikkelsson M. Prognosis of non-specific musculoskeletal pain in preadolescents: a prospective 4 year follow-up study till adolescence. Pain 2004; 110: 550-559.

15 Perquin CW, Hazebroek-Kampschreur AAJM, Hunfield JAM, Bohnen AM, van Suijlekom-Smit LWA, Passchier J et al. Pain in children and adolescents: a common experience. Pain 2000; 87: 51-58.

16 O'Sullivan P, Beales D, Jensen L, Murray K, Myers T. Characteristics of chronic non-specific musculoskeletal pain in children and adolescents attending a rheumatology outpatients clinic: a cross-sectional study. Pediatr Rheumatol 2011; http://www.ped-rheum.com/content/9/1/3.

17 Al Khattat A, Campbell J. Recurrent Limb pain in childhood ('growing pains'). Foot 2000; 10: 117-123.

18 Kaspiris A, Zafiropoulou C. Growing pains in children: epidemiological analysis in a Mediterranean population. Jt Bone Spine 2009; 76: 486-490.

19 Tanamas SK, Wluka AE, Berry B, Menz HB, Strauss BJ, Davies-Tuck M et al. The relationship between obesity and foot pain is related to fat mass and fat distribution but not muscle mass. Arthritis Care Res 2012; 64: 262-268.

20 Moher D, Liberati A, Tetzlaff J, Altman DG, Group TP. Preferred Reporting Items for Systematic Reviews and Meta-Analyses. PLoS Med 2009; 6: e1000097.

21 Braun V, Clarke V. Using thematic analysis in psychology. Qual Res Psychol 2006; 3 77-101.
22 Baker JF, George M, Baker DG, Toedter G, Von Feldt JM, Leonard MB. Associations between body mass, radiographic joint damage, adipokines and risk factors for bone loss in rheumatoid arthritis. Rheumatology 2011; 50: 2100-2107.

23 Buchholz AL, Niesen MC, Gausden EB, Sterken DG, Hetzel SJ, Baum SZ et al. Metobolic acitivity of osteoarthritic knees correlates with BMI. Knee 2010; 17: $161-162$

24 Felson DT, Goggins J, Niu J, Zhang Y, Hunter DJ. The effect of body weight on progression of knee osteoarthritis is dependent on alignment. Arthritis Rheumatol 2004; 50: 3904-3909.

25 Taylor ED, Theim KR, Mirch MC, Ghorbani S. Orthopedic complications of overweight in children and adolescents. Pediatrics 2006; 117: 2167-2174.

26 Krul M, Van Der Wouden JC, Schellevis FG, Van Suijlekom-Smit LWA, Koes BW. Musculoskeletal problems in overweight and obese children. Ann Fam Med 2009; 7: 352-356.

27 de Sá Pinto AL, de Barros Holanda PM, Radu AS, Villares SMF, Lima FR. Musculoskeletal findings in obese children. J Paediatr Child Health 2006; 42: 341-344.

28 Hainsworth KR, Davies WH, Khan KA, Weisman SJ. Co-occurring chronic pain and obesity in children and adolescents: the impact on health-related quality of life. Clin J Pain 2009; 25: 715-721.

29 Stovitz SD, Pardee PE, Vazquez G, Duval S, Schwimmer JB. Musculoskeletal pain in obese children and adolescents. Acta Paediatr 2008; 97: 489-493.

30 Podeszwa DA, Stanko KJ, Mooney 3rd JF, Cramer KE, Mendelow MJ. An analysis of the functional health of obese children and adolescents utilizing the PODC instrument. J Pediatr Orthop 2006; 26: 140-143.

31 Bell LM, Curran JA, Byrne S, Roby H, Suriano K, Jones TW et al. High incidence of obesity co-morbidities in young children: a cross-sectional study. J Paediatr Child Health 2011; 47: 911-917.

32 Bell LM, Byrne S, Thompson A, Ratnam N, Blair E, Bulsara M et al. Increasing body mass index z-score is continuously associated with complications of overweight in children, even in the healthy weight range. J Clin Endocrinol Metab 2007; 92: 517-522.

33 MacFarlane GJ, de Silva V, Jones GT. The relationship between body mass index across the life course and knee pain in adulthood: results from the 1958 birth cohort study. Rheumatology 2011; 50: 2251-2256.

34 Wilson AC, Samuelson B, Palermo TM. Obesity in children and adolescents with chronic pain: associations with pain and activity limitations. Clin J Pain 2010; 26: 705-711.

35 Tsiros MD, Coates AM, Howe PRC, Grimshaw PN, Buckley JD. Obesity: the new childhood disability? Obes Rev 2011; 12: 26-36.

36 Pollack KM, Xie D, Arbogast KB, Durbin DR. Body mass index and injury risk among US children $9-15$ years old in motor vehicle crashes. Inj Prev 2008; 14: 366-371.

37 Pomerantz WJ, Timm NL, Gittelman MA. Injury patterns in obese versus nonobese children presenting to a pediatric emergency department. Pediatrics 2010; 125: 681-685.

38 Zonfrillo MR, Seiden JA, House EM, Shapiro ED, Dubrow R, Baker MD et al. The assoication of overweight and ankle injuries in children. Ambul Pediatr 2008; 8: 66-69.

39 Kessler J, Koebnick C, Smith N, Adams A. Childhood obesity is associated with increased risk of most lower extremity fractures. Clin Orthop Relat Res 2013; 471: 1199-1207.

40 Wearing SC, Henning EM, Byrne NM, Steele JR, Hills AP. The impact of childhood obesity on musculoskeletal form. Obes Rev 2006; 7: 209-218.

41 Shultz SP, Browning RC, Schutz Y, Maffeis C, Hills AP. Childhood obesity and walking: guidelines and challenges. Int J Pediatr Obes 2011; 6: 332-341.

42 Hills AP, Parker AW. Gait characteristics of obese children. Arch Phys Med Rehabil 1991; 72: 403-407.

43 Downing AM, Steele JR, Baur LA. What are the effects of obesity in children on plantar pressure distributions. Int J Obes Relat Metab Disord 2004; 28: 1514-1519.

44 Downing AM, Steele JR, Baur LA. Does obesity influence foot structure and plantar pressure patterns in prepubescent children? Int J Obes Relat Metab Disord 2001; 25: 845-852.

45 Nantel J, Brochu M, Prince F. Locomotor strategies in obese and non-obese children. Obesity 2006; 14: 1789-1794.

46 Shultz SP, Sitler MR, Tierney RT, Hillstrom HJ, Song J. Effects of paediatric obesity on joint kinematics and kinetics during 2 walking cadences. Arch Phys Med Rehabil 2009; 90: 2149-2154.

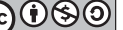

This work is licensed under a Creative Commons AttributionNonCommercial-ShareAlike 3.0 Unported License. To view a copy of this license, visit http://creativecommons.org/licenses/by-nc-sa/3.0/ 